\title{
O COORDENADOR PEDAGÓGICO E SEU PAPEL FORMADOR DENTRO DA ESCOLA
}

\author{
Francisca Soares da Mota Pinto ${ }^{1}$
}

RESUMO: A formação continuada é fundamental para o processo de formação do professor e coordenador pedagógico é o principal responsável pelo esse processo. A realização deste trabalho busca investigar qual a importância do coordenador pedagógico na formação continuada dos professores e como o profissional coordenador pedagógico vem desempenhando esse papel de formador. Para isso, foi realizado um estudo bibliográfico, desenvolvido a partir da análise de autores como: Tardif, Libâneo, Miranda, Saviani, entre outros. E uma pesquisa de campo na E.E.B. Maria Dalva Barbosa de Azevedo ( Anexo Meu Doce Lar) Itapipoca-CE. Constituiu uma pesquisa bibliográfica como fonte de informações que norteiam a formação de profissionais reflexivos. Ao analisar os registros pesquisados percebeu-se que o coordenador pedagógico ocupa um lugar de suma importância no processo de formação continuada que se desenvolve no espaço escolar. Através desse estudo foi possível constatar que o caminho para as mudanças necessárias passa pela coordenação pedagógica, que trabalha em prol do avanço no processo ensino e aprendizagem.

Palavras-chave: Coordenador Pedagógico. Formação Continuada. Professores.

ABSTRACT: the continuing education is fundamental to the process of formation of teacher and educational coordinator is primarily responsible for this process. This work seeks to investigate how important pedagogical coordinator in the continuing education of teachers and as professional pedagogical coordinator comes playing the role of a trainer. To do this, we conducted a bibliographic study, developed from the analysis of authors such as: Tardif, Libâneo, Miranda, Saviani, among others. And a field survey in E.E.B. Maria Dalva Barbosa de Azevedo (Annex My Sweet Home)-Itapipoca CE. A bibliographical research as a source of information that guide the formation of reflective practitioners. By analyzing the logs surveyed perceived that the pedagogical coordinator is of paramount importance in the process of continuing education that develops in the school space. Through this study it was found that the path to the ...

Keywords: Pedagogical Coordinator. Continuing Education. Teachers

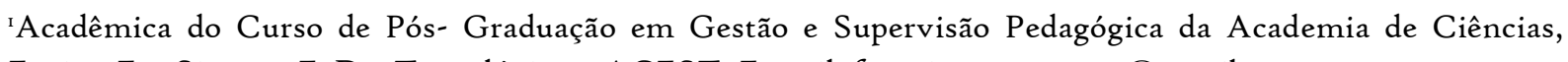
Ensino Em Sistema EaD e Tecnológico-ACEST.E-mail: franciscasoares.geo@gmail.com. 


\section{INTRODUÇÃO}

Diante das expectativas acerca do papel do coordenador pedagógico, onde a sua função formadora tem sido um instrumento a se aperfeiçoar, desenvolvendo também o trabalho do professor. Observa-se no cenário atual que o coordenador pedagógico é um elemento integrador de todos, no processo de ensino e aprendizagem, mantendo as relações interpessoais de maneira saudável, valorizando a for ação dos seus profissionais, ajudandoos efetivamente na construção dos s saberes de sua profissão.

A realização deste trabalho busca investigar qual a importância do coordenador pedagógico na formação continuada dos professores e como o profissional coordenador pedagógico vem desempenhando esse papel formador. Nesse contexto percebe-se que uma das funções do coordenador pedagógico mais importante, é oferecer subsídios para formar os professores de acordo com o projeto político pedagógico da escola usando os preceitos didáticos que pautam a instituição.

Tendo como objetivo geral conhecer a relevância do papel formador do coordenador pedagógico no cenário atual, e, de forma específica procura-se investigar a função do coordenador pedagógico e suas contribuições no processo de formação continuada dos professores; identificar a importância da formação continuada para os professores e analisar como essa formação vem sendo desenvolvida pelo coordenador pedagógico na E.E.B.Maria Dalva Barbosa de Azevedo.

Diante da importância da formação continuada dos professores para que se efetive um processo de ensino e aprendizagem satisfatório, percebe-se no coordenador pedagógico, a peça fundamental para esse processo, pois este atua (ou deveria atuar) dando suporte pedagógico para os professores. No entanto, cabe enfatizar que esse processo de formação efetivado pelo coordenador pedagógico, deve ser realizado com responsabilidade e eficácia.

A realização deste trabalho efetivou-se através de uma pesquisa qualitativa, que é um tipo de pesquisa que permite a possibilidade de estudar os fenômenos que envolvem os seres humanos e as relações sociais em diversos ambientes. E para a realização da mesma inicialmente foi feito uma pesquisa exploratória bibliográfica buscando investigar a 
importância do coordenador pedagógico no processo de formação continuada dos professores, além de sua atuação na escola como mediador entre professores e núcleo gestor e professor e comunidade. E também foi realizada uma pesquisa de campo, na E.E.B. Maria Dalva Barbosa De Azevedo (ANEXO MEU DOCE LAR), situada no município de Itapipoca-CE, visando investigar como vendo sendo realizado o processo de formação continuada pelo coordenador daquela instituição e como os professores veem a formação continuada.

Durante a pesquisa de campo realizada na escola supracitada foi entrevistado um grupo formado por 3 (três) professores atuantes no ensino Fundamental II da referida escola, como também a coordenadora da mesma.

\section{A FUNÇÃO DO COORDENADOR PEDAGÓGICO E AS CONTRIBUIÇÕES NA FORMAÇÃO CONTINUADA DOS PROFESSORES}

Diante da relevância do tema abordado faz-se necessário destacar alguns aspectos históricos sobre a função do coordenador pedagógico até chegar os dias atuais, este que possui grande responsabilidade,que é formar professores no intuito de atingir um ensino de qualidade. A cerca disso Lima e Santos (2007) afirmam que tal profissional é uma peça chave no processo educativo. É bem verdade que o logo do tempo esse profissional passou por uma metamorfose até chegar ao que é hoje, agente principal do processo de formação continuada dos professores.

Pesquisando acerca do histórico da função coordenador pedagógico, percebe-se que essa nomenclatura é atual. Contudo a função já existia, mas em outra perspectiva: a supervisão pedagógica. A supervisão pedagógica foi oficializada no Brasil, com a LDB deI97ı, mas o conceito de supervisão existe desde a época dos jesuítas. Pires (2005, p.23) mencionou a origem da função do coordenador pedagógico desde o inicio da educação jesuítica no Brasil, porém legalmente apresenta como marco inicial a década de 1970, perpassando as funções de prefeito de estudos e de inspetor.

Com a vinda dos primeiro jesuítas, em 1549, dá-se o inicio a organização das atividades educativas em nosso pais. No plano de ensino formulado pelo o Padre 
Manuel da Nóbrega, está presente a função supervisora, mas não se manifesta ainda, a ideia de supervisão. Mas no Plano Geral dos jesuítas o Ratio Studiorum, que é adotado no Brasil especialmente após a morte de Nóbrega, ocorrida em 1570, já se faz presente a ideia de supervisão. (SAVIANI, 2002, p.20)

A ideia de supervisão é antiga no Brasil, desde os primeiros Planos de ensino elaborado para o nosso país, já trazia a função de supervisão pedagógica, porem só posta em pratica a partir da década de 70 do século XX. "A educação se preocupava com o ensino humanista de cultura geral, enciclopédico e alheio á realidade cotidiana de colônia"(VEIGA,2004)..Dessa maneira, tornava-se impraticável um trabalho pedagógico que buscasse uma perspectiva transformadora na educação. Explicita-se no plano geral dos jesuítas, acima citado, a ideia de supervisão educacional na figura do Prefeito de Estudos. Com a expulsão dos Jesuítas e as Reformas Pombalinas o sistema de ensino foi extinto e junto com ele o cargo de Prefeito de Estudos. Então, no que tange aos aspectos educacionais aconteceu um retrocesso, pois alguns professores leigos foram admitidos para as aulas régias iniciadas pelas reformas pombalinas.

A organicidade da educação jesuítica foi consagrada quando Pombal os expulsou levando o ensino brasileiro ao caos, através de suas famosas 'aulas régias', a despeito da existência de escolas fundadas por outras ordens religiosas, como os Beneditinos, os franciscanos e os Carmelitas". (NISKIER, 20or, p. 34)

O pensamento de supervisão continuava presente, agora, englobada nos aspectos político-administrativos (inspeção e direção) da figura do Diretor geral; e também nos aspectos de direção, fiscalização, coordenação e orientação do ensino, na figura dos Diretores dos Estudos.

\footnotetext{
Caracterizando-se como educação nacional, a educação no Império, por suas peculiaridades, integra o segundo período da História da Educação Brasileira, que se inicia em 1759 e que finda com a República em i889. Embora permaneçam unidos Igreja e Estado, nesse vasto período se desenvolve "[...] um processo de secularização do ensino, assumindo o Estado a responsabilidade de cuidar da Instrução Pública" (CARVALHO, 1972, p. 2)
}

Com a Independência do Brasil é estabelecida a primeira Lei para a instrução pública que instituiu as Escolas de Primeiras Letras baseadas no "Ensino Mútuo". "Em Is de outubro de 1827 , é aprovada pelo Senado a primeira lei específica sobre a instrução no Brasil, cujo teor determinava, entre outras medidas, a construção de escolas de primeiras letras onde se fizesse necessário" (SAVIANI, 2002). Método que concentra no professor as funções de docência e supervisão, ou seja, instruir os monitores e supervisionar as atividades de ensino e aprendizagem dos alunos. 
O regulamento de 17 de fevereiro de 1854 , no âmbito das Reformas Couto Ferraz, estabeleceu como missão do inspetor geral supervisionar, seja pessoalmente, seja por seus delegados ou pelos membros do Conselho Diretor, todas as escolas, colégios, casas de educação, estabelecimentos de instrução primária e secundária, públicos e privados. Além disso, cabia também ao inspetor geral presidir os exames dos professores e lhes conferir o diploma, autorizar a abertura de escolas particulares e até mesmo rever os livros, corrigi-los ou substituí-los por outros. (SAVIANI, 2002, p. 23).

$\mathrm{O}$ inspetor deveria ser um indivíduo de prestigio pessoal e conhecimento com pessoas importantes e com autoridades constituídas.

O regulamento educacional do período imperial estabelecia que a função coordenadora devesse ser exercida por agentes específicos para a coordenação permanente, essa missão foi atribuída ao Inspetor Geral que supervisionava todas as escolas, colégios, casa de educação pública e privada (LIBÂNEO, 2002, p. 59).

Suas atribuições eram fiscalizar e padronizar as rotinas escolares ás normas oficiais emanadas das autoridades centrais, por essa razão exercia essas funções como "autoridade do sistema", através de visitas corretivas e de registros permanentes para confecção de relatórios a serem encaminhados aos órgãos centrais. Com o objetivo de fiscalizar o grau maior ou menor de desvio da ação pedagógica em relação aos padrões estabelecidos pela Lei. Com a discussão sobre a organização de um sistema nacional de educação, a ideia de supervisão vai ganhando contornos mais nítidos. Baseava-se em dois requisitos: A organização administrativa e pedagógica do sistema e a organização das escolas na forma de grupos escolares.

No início do Período Republicano, o papel do supervisor era exercido pelo inspetor que deveria ser uma pessoa qualificada, experiente e sensível para com técnicos pedagógicos do processo de ensino-aprendizagem.

Dentre suas principais atribuições podemos citar: orientar, controlar, supervisionar, fiscalizar e inspecionar todo o processo educacional através de conferências, palestras visitas, acompanharem o desenvolvimento do currículo nos estabelecimentos, com objetivos de orientar pedagogicamente os professores mais jovens, buscando eficiência, introduzindo inovações, modernizando os métodos de ensino e promovendo um acompanhamento mais atento do currículo pleno nos estabelecimentos (FERREIRA, 2003, p. 32). 
Surgem, então na década de 20, os profissionais da educação, também conhecidos com "técnicos em escolarização" e concomitantemente é criada a Associação Brasileira de Educação por iniciativa de Heitor Lira. A Associação Brasileira de Educação foi um elemento instigante aos chamados, técnicos em educação. A reforma João Luís Alves em I924 criou o Departamento Nacional de Ensino e o Conselho Nacional de Ensino separando, assim, a parte administrativa da parte técnica que antes estavam unidas num mesmo órgão o Conselho Superior de Ensino. (MIRANDA,2012 p.13). Esse foi um salto importante para a criação do Ministério da Educação e Saúde Pública e essa divisão favoreceu para o surgimento do cargo de supervisor distinta da figura do diretor e inspetor. Assim a parte técnica ficava a cargo do inspetor, já a parte administrativa ficava a cargo do diretor. " $\mathrm{Na}$ década de 30 , a sociedade brasileira sofre muitas transformações sociais, econômicas e políticas que refletem no modelo educacional. A crise de 1929 desencadeia a decadência do café e a Revolução de 30"(MIRANDA,2012 p.13). Quando Vargas chega ao poder cria o Ministério da Educação e Saúde Pública. Sob a influência da política do Liberalismo surge o Manifesto dos Pioneiros da Escola Nova,enfatizando a ideia de uma escola que atendesse uma sociedade urbana e industrial. $O$ aparecimento da função de supervisor educacional está tangenciada com as vinculações do Brasil com os Estados Unidos. O novo modelo econômico pautado no desenvolvimentismo e nos financiamentos estrangeiro, trouxe para o país também um modelo educacional pautado nas ideias americanas, e a partir de então e Supervisor passa a ser uma figura de grande importância na escola.

Art. 62. A formação do orientador de educação será feita em cursos especiais que atendam às condições do grau do tipo de ensino e do meio social a que se destinam.

Art. 63. Nas faculdades de filosofia será criado, para a formação de orientadores de educação do ensino médio, curso especial a que terão acesso os licenciados em pedagogia, filosofia, psicologia ou ciências sociais, bem como os diplomados em Educação Física pelas Escolas Superiores de Educação Física e os inspetores federais de ensino, todos com estágio mínimo de três anos no magistério.

Art. 64. Os orientadores de educação do ensino primário serão formados nos institutos de educação em curso especial a que terão acesso os diplomados em 
escolas normais de grau colegial e em institutos de educação, com estágio mínimo de três anos no magistério primário.

Art. 65. O inspetor de ensino, escolhido por concurso público de títulos e provas vetado ............ deve possuir conhecimentos técnicos e pedagógicos demonstrados de preferência no exercício de funções de magistério de auxiliar de administração escolar ou na direção de estabelecimento de ensino. (BRASIL, I96ı, p. II)

Com instalação da Ditadura Militar, a educação passa a ser oferecida nos moldes da Pedagogia Tecnicista, há um descaminho. $\mathrm{O}$ autoritarismo e a repressão são os alicerces dessa pedagogia, o trabalho é fragmentado e mecanicista, da mesma forma que numa fábrica, busca-se a burocratização, a eficácia e resultados imediatistas(MIRANDA,2012). Percebe-se que nesse período a escola torna um lugar para criar pessoas que não pensavam, produziam de forma repetitiva,

Constituiu-se então, um estado capitalista, do ponto de vista econômico, autoritário em sua política, e liberal no ponto de vista ideológico, excluindo uma parcela significativa da população dos benefícios da população do crescimento econômico. (RAPOSO, 1994, p. 33)

O governo aprovou as Reformas de $\mathrm{I}^{\circ}$ e $2^{\circ}$ graus e Universitária, sendo que esta reformou o Curso de Pedagogia que ganhou novas habilitações: administração, inspeção, supervisão e orientação, com isso a função de supervisor educacional é profissionalizada(MIRANDA,2012 p.14). Agora o supervisor educacional passa a ser um especialista em educação, e a sua função agora, era controlar o processo de produção caracterizada de coordenação e direção do trabalho. O papel do supervisor era oferecer treinamentos para professores onde discutiam e difundiam os fundamentos de organização dos processos de trabalho. Em momento onde o país passava pelo um grande desenvolvimento econômico e estabilidade política a função do Supervisor Educacional é refletida nesse contexto histórico.

A Supervisão Educacional foi criada num contexto de ditadura. A Lei 5.692/71 a instituiu como serviço especifico da Escola de ıo. E 2ํ․ Graus (embora já existisse anteriormente). Sua função era, então, predominantemente tecnicista e controladora e, de certa forma, correspondia à militarização Escolar. No contexto da Doutrina de Segurança Nacional adotada em 1967 e no espírito do AI-5 (Ato Institucional n. 5) de 1968, foi feita a 
reforma universitária. Nela situa-se a reformulação do Curso de Pedagogia. Em 1969 era regulamentada a Reforma Universitária e aprovado o parecer reformulador do Curso de Pedagogia.

$\mathrm{Na}$ década de 8o, a crise socioeconômica e a Nova República iniciam uma nova fase.(MIRANDA,2012 p.17) Influenciadas pelo neoliberalismo, surge nesse contexto uma força maior da luta operaria, que vem de encontro com a iniciativa dos professores de lutar para terem novamente o direito de poder estarem participando de políticas publicas educacionais, uma vez que esse direito tinha sido retirado durante o regime militar e poderem está também, lutando pela recuperação da escola pública. A primeira conferência Brasileira de Educação constitui um espaço para discussão e disseminação da concepção crítica da educação e a Pedagogia Crítica ganham espaço no cenário educacional.(MIRANDA,2012 p.17).

O fazer pedagógico não está centrado no professor ou no aluno, mas na questão central da formação do homem; está voltada para o ser humano e sua realização na sociedade e comprometida com os interesses dos menos favorecidos economicamente. A realidade é múltipla e diversa e a educação deve atendê-la.

O mundo contemporâneo é marcado pelo neoliberalismo, acentuando-se e ampliando-se as formas de exclusão social e cultural (FERREIRA,2003). A globalização reflete no âmbito educacional no que se refere à organização do trabalho pedagógico, delegando uma série de atribuições ás escolas, aos professores e alunos.

As políticas governamentais passaram a ser regidas pela ordem do mercado, o que alterou as condições de trabalho e de profissionalidade docente, impondo inúmeros desafios às escolas e aos seus sujeitos, notadamente o professor, que é, hoje, posto em xeque, principalmente por sua condição de fragilidade em trabalhar com os desafios da época (...) (FERNANDES, 2009, p. 2)

A Lei de Diretrizes e Bases da Educação no. 9.394/96 traz em seu texto a necessidade de uma formação para os coordenadores pedagógicos. 
Art. 64. A formação de profissionais de educação para administração, planejamento, inspeção, supervisão e orientação educacional para a educação básica, será feita em cursos de graduação em pedagogia ou em nível de pósgraduação, a critério da instituição de ensino, garantida, nesta formação, a base comum nacional. (BRASIL i996, p. 20)

Percebe-se o surgimento de um novo especialista, o coordenador pedagógico, que é o supervisor com uma nova compreensão, um intelectual que coordena as ações do grupo, para favorecer o processo de construção de saberes, numa visão democrática. De acordo com FERREIRA (2003, p. 179) a função do coordenador, vem passando de controlador e direcionador para estimulador do trabalho docente. Portanto a partir desta compreensão simples, entendem-se as claras mudanças de padrões, de função normativa, prescritiva, para tornar-se uma ação crítica e reflexiva aliada ao professor.

A coordenação pedagógica deve ser lembrada como um produto genuíno da pedagogia nova, por onde se formalizou sua conotação de mentora na escola, do enfoque psicológico estrito da educação. Não é preciso muito esforço para chegar a uma definição-padrão de suas atribuições; um serviço que ocupa da coordenação pedagógica escolar voltada a orientação dos professores e alunos, visando ao desenvolvimento de suas potencialidades (LIBÂNEO, 2002, p.72).

O papel do coordenador pedagógico e a sua importância na formação continuada do professor está evidente na fala de FERREIRA (2003, p. 179) Manter um clima de abertura, cordialidade, encorajamento, fortalecer o sentimento grupal; trabalhar com professores, partilhar ideias, estimulando e fortalecendo as lideranças.

O coordenador pedagógico, precisa antes de mais nada, saber que para sua pratica ter significância, ele precisa está dando subsidio aos professores no que tange aos assuntos inerentes da escola, que sabemos que são muitos, por isso é tão importante que este profissional esteja sempre bem informado e por dentro de assuntos relacionados a educação como um todo e principalmente da escola.

Supervisionar e administrar as atividades desenvolvidas na formação continuada é um dos focos de fundamental importância no trabalho do gestor. Para tanto, faz-se necessário à criação de rotinas de supervisão que permita acompanhar o que ocorre em todos os grupos e espaços da instituição, como por exemplo: organização do espaço, acompanhamento do planejamento do professor (NÓVOA, 2002, p. 59). 
$\mathrm{Na}$ citação a cima explica-se de forma coerente a indispensável supervisão acompanhada de orientação fundamentada em conceitos e reflexões. LÜCK (2011, p. 43) destaca o coordenador como facilitador de ações, isto é de assistir os atuantes no processo educativo na organização e análise de sua tarefa; na determinação de procedimentos; na divisão e tomada de responsabilidade. Entende-se nessa fala que todo o processo está em torno da melhoria da aprendizagem, orientando e aprimorando atitudes, habilidades e conhecimento do professor. Diante deste assunto, SOUZA (2006, p. I29) afirma que a gestão escolar, por sua natureza política, funde-se entre gestão e poder; e o domínio legítimo sobre as relações de poder é o domínio sobre os processos de gestão escolar.

Assim, o Coordenador Pedagógico atua de forma a conciliar o poder e as relações educacionais. Entre essas relações encontra-se o elo em maior evidência no trabalho do coordenador, justamente, a relação professor e coordenador. Este atuando como um estimulador da formação continuada. Compete ao Coordenador Pedagógico gerar condições e ambientes adaptados à concretização de novas vivências, para o professor se encaixar no âmbito escolar como ator do processo, com a finalidade de promover a prática educadora transformada. Aquilo que o professor diz e faz é midiatizado pelo seu corpo, pelos seus afetos, seus sonhos, seus fantasmas e suas convicções. NÓVOA, (1992, p.189). A transformação comportamental do professor em reconstruir suas práticas pedagógicas, passa pelo imperativo de realizar um trabalho de forma coletiva, associando as próprias concepções, culminando no estabelecimento de diretrizes educacionais adaptadas à comunidade escolar.

\footnotetext{
A abertura dos portões e muros escolares deve estar acompanhada da nova proposta pedagógica que a exija. Se as escolas não estiver predispostas a essa mudança. A gestão e a melhoria da qualidade será expressões esvaziadas de qualquer conteúdo substantivo (SPÓSITO, 2005 p.55).
}

A escola deve está sempre preparada para os novos desafios, sempre visando uma transformação eficiente no que diz respeito ao crescimento educacional a melhoria no ensino aprendizado por ela oferecida. Buscado para dentro da escola a comunidade escolar, pois a parceria com esta é fundamental, afinal o trabalho oferecido pela escola é para a 
comunidade escolar, e na Gestão democrática isto se torna indispensável, e a figura do coordenador pedagógico é primordial para que isso ocorra, afinal ele sempre deve agir como um elo entre, professores, direção e comunidade escolar. O coordenador pedagógico, deve ter ciência dentre as suas funções uma delas é articular a coletividade dentro da escola, ele precisa unir as concepções individuais, aliando novas ideias e saberes, com o objetivo de fazer uma educação voltada para as necessidades pedagógicas da nova geração de alunos, pois, ensinar exige conhecimento, segurança, competência profissional, além de discernimento em entender que a educação pode ser uma agente de transformações sociais. Admitida a hipótese que o coordenador é um agente na formação continuada de professores no âmbito escolar, vários autores dedicam-se a refletir e discorrer acerca das especificidades de sua tarefa e as competências e habilidades indispensáveis a essa função.

\begin{abstract}
A função primeira do coordenador pedagógico é planejar e acompanhar a execução de todo o processo didático-pedagógico da instituição, tarefa de importância primordial e de inegável responsabilidade e que encerra todas as possibilidades como também os limites da atuação desse profissional. Quanto mais esse profissional se voltar para as ações que justificam e configuram a sua especificidade, maior também será o seu espaço de atuação. Em contrapartida, o distanciamento dessas atribuições seja por qual motivo for, irá aumentar a discordância e desconhecimento quanto às suas funções e ao seu papel na instituição escolar (PIRES, 2004, p. I82).
\end{abstract}

O coordenador envolve as competências e saberes específicos de cada faixa etária. Quem atua na Educação infantil, por exemplo, percebe que a organização dos ambientes, Educação e cuidado são indissociáveis nesse estágio. Assim, norteia e orienta os professores a referenciar as formas de conviver e aprender das crianças pequenas. Nos primeiros anos do Ensino Fundamental, o coordenador precisa se atualizar e conhecer as teorias e práticas de alfabetização. Dessa maneira, orienta sua equipe para construir nas crianças comportamentos leitores e escritores. Nos anos seguintes do Ensino Fundamental, o coordenador continua dispondo situações para discutir os processos de ensino e de aprendizagem, as didáticas de cada disciplina, a interdisciplinaridade e a avaliação dos alunos. Leva a equipe docente a refletir e chegar a acordos sobre esses pontos.

Pesquisar temas de interesse dos professores colabora para construção de uma reflexão, isso acontece para que os saberes docentes sejam construídos segundo as 
suas ferramentas específicas, que se misturam no cotidiano e na prática, nas suas necessidades, recursos e limitações. (TARDIF, 2004, p. 65)

A clareza sobre aonde chegar e o pacto com o aprender guiam a busca de saídas e práticas que são diversas. $O$ progresso profissional permanente é uma condição para o exercício da docência de qualquer um que escolhe ser professor, que se torna independente de sua formação inicial e de sua condição sócio cultural. A formação continuada de educadores é uma necessidade intrínseca à atividade profissional, que pode ir além da oferta de cursos esporádicos, mas possam apresentar-se integrados no cotidiano escolar, como componente essencial da práxis docente. Como será disposto sobre o Histórico do Coordenador Pedagógico, essa função vem se reorganizando ao longo do tempo e se adaptando não só às novas diretrizes legais, mas também às demandas da escola, a qual define o papel do coordenador como um gestor pedagógico da instituição; mas ainda se deparam com inquietações e desafios, muitos deles oriundos de uma visão, que ainda existe, de que são fiscais ou que têm um papel de vigiar.

A formação continuada é compreendida como um processo permanente de desenvolvimento profissional de: estudo, atualizações, discussões e trocas de experiências. A formação continuada só faz sentido quando é também valorizada individualmente: só é possível aperfeiçoar o professor que queira crescer (FUSARI, 2007, p. 8I).

Possuir argumentos para motivar os professores, é algo indispensável para o coordenador pedagógico, pois este deve promover momentos de aprendizado para os professores, mas vale ressaltar que para aprender é necessário querer, assim a motivação deve vir antes mesmo que ocorra os momentos de estudos.

Percebe-se na contemporaneidade, que uma das principais funções do coordenador pedagógico é atuar como agente formador, principalmente em conhecimento de áreas pedagógica, de modo que venha de encontro com a realidade e as necessidades da escola. Portanto, as diretrizes e a realidade indicam que o coordenador pedagógico deve ser essencialmente um formador, que o tema do trabalho do coordenador deve ser a aprendizagem e não só o ensino. "Os saberes que nascem da experiência e são, pela a 
experiência, validados incorporam-se à vivencia individual e coletiva sob a forma de hábitos e de habilidades,de saber fazer e de saber ser."(CANDAU,2003,p.1560)

Com essa visão, fica claro que atuação do coordenador pedagógico não é entendida como uma atividade simplesmente técnica, mas que se constitui em uma prática intelectual, complexa, que demanda condições de tempo que viabilizem a efetivação de sua atribuições, espaço pra encontro com professores, alunos, gestores, pais clima institucional, cultura colaborativa e validação da importância na formação continuada. Requer, ainda, espaços formativos regulares e específicos para esse grupo de profissionais da rede que demanda,assim com os demais, a formação continua. Envolver o grupo na intenção do trabalho,alinhando os saberes do grupo no sentido de planejar e fazer um trabalho co qualidade e pensando coletivamente. De acordo com SOUZA e RAMOS (2004, p.5) pessoas de mesmo nível hierárquico tendem compartilhar características comuns, tornando a comunicação mais viável, sendo um veículo facilitador par o desenvolvimento de dinâmicas de grupo entre professores. Outro aspecto importante é considerar os conhecimentos advindos dos professores, valorizando-os sempre que possível, e utilizando-os como ponto de referência para a formação.

As subjetividades são inerentes aos saberes docentes construído na prática profissional, por isso, deve ser respeitado o professor como sujeito de sua prática. Estes também podem ser importantes indicadores para a compreensão das causas de possíveis resistências.(TARDIF,2004, P.228)

Diante de possíveis resistências a novos saberes, por parte do corpo docente, é importante a função do coordenador pedagógico, onde este, usando-se da validação, irá valorizar o conhecimento do professor,e ao mesmo tempo deixando claro a importância de adquirir novos conhecimentos. Nada disso é satisfatório se o próprio coordenador não estiver em atitude abertura para a aprendizagem, reconhecendo a necessidade da formação contínua como também uma gestão de sua autoformação.

Com este estudo percebe-se que a articulação que o coordenador pedagógico deve desenvolver na escola contribui de forma direta para o processo de formação de professores. Entre as diversas atribuições está o fato de seguir o trabalho docente. 


\section{A IMPORTANCIA DA FORMAÇÃO CONTINUADA PARA OS PROFESSORES}

O cenário atual se encontra imerso em discursos sobre práticas docentes muito mais voltadas para a teoria do que mesmo para a prática, onde se percebe que os programas de formações continuadas não atendam os anseios dos professores, que ainda se encontram em um estagio de individualidade, algo que para os dias atuais encontra-se ultrapassado no que diz respeito aos caminhos, onde a ideia de coletividade pode ser positiva não só para o trabalho docente, mas também para a instituição.

$$
\begin{aligned}
& \text { valorização de paradigmas de formação que promovam a preparação de } \\
& \text { professores } \\
& \text { do seu próprio desenos, que assumam a responsabilidade } \\
& \text { na implementação das políticas educativas ( NÓVOA, 1992p. } 27 \text { ). }
\end{aligned}
$$

$\mathrm{Na}$ verdade os professores precisam sentir-se seguros para que eles mesmos possam promover suas próprias praticas educativas, e consequentemente as políticas pedagógicas, uma vez que, precisam desenvolver espírito de coletividade, visando um melhoramento nas suas praticas pedagógicas.

A formação continuada tem como principal objetivo desenvolver o trabalho dos professores e consequentemente melhorar suas praticas pedagógicas, assim como também as relações interpessoais dentro da escola, pois as mesmas quando bem sucedidas, melhoram o local de trabalho e, é evidente que quem trabalha contente, trabalha melhor. Diane do exposto, vê- na figura do coordenador pedagógico o elemento chave para que ocorra essa formação, e vai depender muito deste profissional, para que essas formações tenham realmente significados para os docentes. "Importante se faz destacar que um dos principais papéis do coordenador pedagógico é o de formador, desta maneira, ele é o responsável por mediara proposta de formação continuada dentro do espaço educacional, ou seja,a escola."(COLARES e ROCHA, 2016 p.39).

O coordenador pedagógico aqui entendido como o principal agente do processo de formação continuada, deve entender que esse processo deve ser visto não só como um aprimoramento do profissional professor, mas consequentemente da melhoria do processo de ensino e aprendizagem dos alunos. 
[...]acerca do trabalho pedagógico, entende-se que a prática do coordenador pedagógico deve ter como prioridade o trabalho deformação continuada com professores da instituição em que atua, visto que a formação é importante tanto para os professores quanto para os alunos, uma vez que os resultados das formações se refletem no trabalho desenvolvido em sala de aula com os educandos.(COLARES e ROCHA,2016 p.39).

De acordo com o supracitado, a formação continuada está diretamente ligada aos bons rendimentos dos alunos, pois um bom trabalho realizado por parte dos docentes reflete diretamente no aprendizado dos discentes.

A formação para um profissional é antes de mais nada, segurança no que faz, e através disto conquistar respeito perante a sociedade, fortalecendo a credibilidade de suas instituições no tocante dos serviços que prestam.

\footnotetext{
Entre as condições de profissionalização está uma sólida formação aliada à conquista da autonomia individual e coletiva. Deste modo, a formação continuada no Brasil constitui um dos elementos de desenvolvimento profissional dos professores, pois complementa a formação inicial e constitui condição de acesso para níveis mais elevados na carreira docente. (ROMANOWSKI E MARTINS, 2009, P. 287)
}

As formações continuadas auxiliam o professor em seu crescimento profissional, uma vez que um bom profissional tende a se reciclar, a se atualizar para continuar contribuindo com o seu trabalho de forma eficaz.

A falta de formação por partes dos professores não é algo recente, há relatos do período imperial onde os inspetores relatavam sobre a falta de formação dos professores. Tentando solucionar este problema foram realizados teste descobrissem pessoas com vocação para lecionar, criaram também a função de professores-mestre e também os cursos normais. Tudo isso visando o melhoramento profissional dos professores do período.

Um outro momento que as formações continuadas para professores tiveram impulso, foi na década de 40 do século XX,( ROMANOWSKI E MARTINS, 2009 p.289) com a criação de vários programas com o PABAEE, Programa de Assistência BrasileiroAmericana, para formar professores de Escolas Normais Oficiais, o INEP, Instituto 
Nacional de Estudos Pedagógicos, para orientar a formulação de políticas públicas e realizar formações continuadas em várias regiões brasileiras.

\begin{abstract}
Nesse período, o escolanovismo é dominante e insere-se na formação docente. A ênfase da formação considerava práticas de laboratório educativo, isto é, o professor experimentava as propostas indicadas nos estudos teóricos e com base nesta experiência mudaria sua prática pedagógica. Nesse processo, a teoria constitui-se guia da prática.(ROMANOWSKI E MARTINS, 2009, P. 289)
\end{abstract}

De posse do conhecimento adquirido e após os experimentos das ideias os professores iriam para a sala de aula para desenvolver as novas praticas pedagógicas.

Desse a modo a formação continuada passa a ter mais espaço no cenário educacional, e a partir da década de 1960, já leva a ideia de formação complementar, como forma de treinamento, que poderiam ser realizados em forma de palestras ou curso de curta duração. Com o passar do tempo a formação continuada vai se tornando cada vez mais necessária, uma vez que seria um aperfeiçoamento profissional. A respeito disso. (ROMANOWSKI E MARTINS, 2009 p 288) falam: No final da década de 1970, a formação continuada assume a forma de aperfeiçoamento, atualização, capacitação, educação permanente e educação continuada.

Com isso a partir da década seguinte, a formação continuada passar tem muito importância para os professores, pois passa a ser reconhecida como titulação conseguida após o ingresso no mundo educacional, podendo ser usada pra promoção profissional.

A partir da década de 1990, muda-se essa perspectiva, e formação continuada leva em conta o professor como o principal agente de transformação da suas praticas pedagógicas e esse momento deveriam ser realizados no chão das próprias escolas, onde esses momentos seriam usados para reflexões sobre os fazeres pedagógicos e de interação entre os professores, onde este estariam debatendo sobre a realidade vivenciada por eles com o intuito de melhorar a qualidade do ensino oferecido por eles.

A formação do educador é um processo, acontecendo no interior das condições históricas que ele mesmo vive. Faz parte de uma realidade concreta determinada, que não é estática e definitiva. É uma realidade que se faz no cotidiano. Por isso, é 
importante que este cotidiano seja desvendado. O retorno permanente da reflexão sobre a sua caminhada como educando e como educador é que pode fazer avançar o seu fazer pedagógico (CUNHA, 2006 p. 22).

Agora a formação continuada passa ter caráter reflexivo da pratica pedagógica dos professores, onde estes estarão em conjunto refletindo acerca de suas praticas pedagógica e da realidade dos mesmos. É a formação estabelecida no cotidiano escolar, nas reuniões programadas no horário complementar docente, arranjados com os tempos que os professores tem disponíveis para seus estudos, atividades de formação continuada na escola, com a gestão do coordenador pedagógico.

Entende-se que a formação do professor tem inicio nos cursos de graduação para professores, nas universidades, sendo que a formação do professor vai acontecer de fato na sala de aula, no contato com os alunos, vivenciando os desafios de ser professor, falando sobre suas praticas, desafios, angustias e lamentações com os demais professores.

A escola é o lugar onde os professores mais aprendem a sua profissão, é lá com seus pares, com seus alunos, que esses profissionais vão construindo sua identidade profissional, vão dando sentido à profissão, (re) fazendo o caminho com os caminhantes na organização da escola.(ASSUNÇÃO e FALCÃO, 2015, P.13)

Assim, percebe-se que a escola é sem dúvida o local mais apropriado para que haja uma formação eficaz para o professor.

A cada dia que se passa torna-se mais visível que as formações iniciais oferecidas pelas instituições se tornam ineficiente, para que realmente um processo formativo é necessário o chão da escola o contato direto com os alunos. Cabendo citar a importância do coordenador pedagógico para esse feito.

Parto da compreensão de que o coordenador pedagógico exerce um relevante papel na formação continuada do professor em serviço, e esta importância se deve à própria especificidade de sua função, que é planejar e acompanhar a execução de todo processo didático-pedagógico da instituição (GEGLIO, 2004, p. IIs).

Assim, entende-se que o coordenador pedagógico não pode se descuidar de sua função principal, a de formador. 
Em virtude das transformações as quais a sociedade vem passando, com a inserção da tecnologia, da velocidade em que acontecem as comunicações, é que se faz necessário a atualização, mediante ao aprofundamento na área em que atua, tendo também a sensibilidade de conhecer a realidade dos seus alunos e da comunidade escolar buscando as melhores formas para produzir o conhecimento. Desse modo, para que haja um bom professor, e com ações de qualidade faz-se necessário que se tenha uma formação, também de qualidade, é necessário portanto ter espírito de coletividade, lidar e saber trabalhar com a diversidade, entender de gestão (embora que superficialmente) e trabalhar de maneira lúdica e interdisciplinar.

Como resposta a essa nova perspectiva da escola reflexiva, da formação inicial e contínua, do desenvolvimento profissional do professor, parece haver um certo consenso que o desenvolvimento profissional ocorre durante a vida do professor, na sua interação com a sua prática, com o coletivo escolar e com os contextos organizacionais no qual estão inseridos.(RIVAS, LEAL e CAPELINI,2005, p. 6).

É bem visível que só se torna professor verdadeiramente, quando o individuo põe seus pés na escola, na sala de aula, pois é, sem dúvida esse local o mais apropriado para a formação continuada de qual qualquer profissional da área educacional, mas, preferivelmente o professor.

Com vista nesse processo de formação que o professor necessita, vê-se na formação continuada uma forma de aperfeiçoamento desses profissionais, buscando novas técnicas para atender as reais necessidades do publico discente. Visando dessa forma um processo de ensino e aprendizagem eficaz. "A formação não se faz antes da mudança, faz-se durante, produz-se nesse esforço de inovação e de procura dos melhores percursos para a transformação da escola" (NÓVOA, 1997, p.28)

A atuação de um coordenador pedagógico deve subsidiar o trabalho do professor, sempre em busca de articular o ensino-aprendizagem, oportunizando também a simultaneidade do trabalho em equipe. Além de estabelecer objetivos para o ensino, específicos e gerais, ele determina as linhas de atuação em função dos objetivos da comunidade e dos discentes, seleciona os conteúdos curriculares, sugere metas a serem atingidas, avalia e acompanha o resultado das propostas pedagógicas, analisa o desempenho dos docentes, alunos e equipe escolar como um todo. Além disso, ele tem que realizar atividades rotineiras demandadas pela dinâmica escolar.(COLARES e ROCHA, 2016 p.82). 
Percebe-se a partir da citação que o coordenador pedagógico possui múltiplas funções, e cabe a este saber atuar diante disto, sem deixar de lado os principais: a formação continuada dos professores e o aprendizado do aluno.

Diante desse contexto, percebe-se na formação continuada, um meio de solucionar problemas que estejam ocorrendo naquele espaço, a escola, meramente um amontoado de títulos que de nada serviram se não postos em praticas o que foi estudado.

\begin{abstract}
o significado das práticas de formação; faz-se necessário compreender que um processo de formação de caráter contínuo, reflexivo, dialógico, colaborativo, deve ser alimentado por situações que o permitam desenvolver-se como tal. Portanto, não se deve confundi-lo com busca desenfreada por titulação, por acúmulo de conhecimentos e técnicas, nem tão pouco permeado por atividades estanques com fim em si mesmas, mas por um trabalho que se permita reflexivo, consciente de suas limitações várias, onde a prática seja o ponto de partida.(ASSUNÇÃO E FALCÃO, 2015, P. I4)
\end{abstract}

Portanto, faz-se necessário uma reflexão a cerca das formações continuadas no intuito de que essas aconteçam visando algo real, partindo de uma necessidade que possa ser norteadora de uma prática que ocorra para solucionar problemas dentro das limitações encontradas, porém visando sempre aprendizagem dos alunos.

\title{
4. METODOLOGIA
}

A realização deste trabalho efetivou-se através de uma pesquisa qualitativa, que é um tipo de pesquisa que permite a possibilidade de estudar os fenômenos que envolvem os seres humanos e as relações sociais em diversos ambientes. A pesquisa qualitativa é de particular relevância aos estudos das relações sociais devido à pluralização das esfera da vida. (UWE FLICH,2009). E para a realização da mesma inicialmente foi feito uma pesquisa exploratória bibliográfica buscando investigar a importância do coordenador pedagógico no processo de formação continuada dos professores, além de sua atuação na escola como mediador entre professores e núcleo gestor e professor e comunidade.

A pesquisa bibliográfica busca a resolução de um problema (hipótese) por meio de referenciais teóricos publicados, analisando e discutindo as várias contribuições científicas. Esse tipo de pesquisa trará subsídios para o conhecimento sobre o que foi pesquisado, como e sob que enfoque e/ou perspectivas foi tratado o assunto apresentado na literatura científica. (BOCCATO, 2006, p.266) 
A partir das leitura e observações teóricas percebe-se a contribuição desse profissional para o processo de formação continuada dos professores, bem como na supervisão do processo de ensino e aprendizagem dos alunos.

Do ponto de vista dos objetivos este trabalho busca proporcionar uma maior intimidade com o tema e a questão levantada; envolvendo levantamento bibliográfico através de material já publicados como livros, artigos, internet e etc.

E também foi realizada uma pesquisa de campo, na E.E.B. Maria Dalva Barbosa De Azevedo (ANEXO MEU DOCE LAR), situada no município de Itapipoca -CE, visando investigar como vendo sendo realizado o processo de formação continuada pelo coordenador daquela instituição e como os professores veem a formação continuada. A ideia central da pesquisa engloba o coordenador pedagógico como agente formador dentro da escola.

A pesquisa de campo é o tipo de pesquisa que pretende buscar a informação diretamente com a população pesquisada. Ela exige do pesquisador um encontro mais direto. Nesse caso, o pesquisador precisa ir ao espaço onde o fenômeno ocorre, ou ocorreu e reunir um conjunto de informações a serem documentadas [...](GONÇALVES,200I, p. 67)

Durante a pesquisa de campo realizada na escola supracitada foi entrevistado um grupo formado por 3 (três) professores atuantes no ensino Fundamental II da referida escola, como também a coordenadora da mesma.

As entrevistas foram compostas por io (dez) perguntas aberta e tiveram como principal finalidade, levantar informações dos entrevistados a cerca da importância da formação continuada para os professores; como esse processo pode está contribuindo para a melhoria do trabalho dos docentes; de que forma é encarada a ideia de formação uma forma de atualização e principalmente como a coordenadora da escola está atuando nesse processo. Todos os envolvidos nas entrevistas responderam as perguntas de livre e espontânea vontade podendo apresentar assim a sua opinião sobre os assuntos supracitados. O período de realização da entrevista se deu entre a segunda e terceira semana do mês de julho de 2018 (dois mil e dezoito). 


\section{I ANALISE E DISCUSSÕES}

Entendendo a importância de fazer pesquisas que permitam um diagnóstico da problemática investigada de forma contextualizada e que possibilitem conhecer, de moda aprofundado, a visão dos sujeitos envolvidos, esta sessão destina-se à apresentação dos resultados obtidos durante a investigação junto aos sujeitos, fazendo um diálogo entre as conclusões alcançadas pelos pesquisadores e o estudo dos autores adotados nesta pesquisa. (ASSUNÇÃO e FALCÃO, 2015).

Durante a pesquisa de campo realizada na escola Maria Dalva Barbosa de Azevedo (ANEXO MEU DOCE LAR), optamos por realizar a pesquisa por amostragem onde foram selecionados uma equipe pedagógica composta pelo um grupo de três professores e a coordenadora da referida escola.

TABELA- de amostragem dos sujeitos envolvidos na pesquisa

\begin{tabular}{|l|l|l|}
\hline Sujeito da pesquisa & Quantidade & Turmas que lecionam \\
\hline Professores & 3 & 6o ao 9ㅇ \\
\hline Coordenadora Pedagógica & I & - \\
\hline
\end{tabular}

A escolha dos participante ocorreu mediante a disponibilidade dos mesmos em aceitarem participar da pesquisa e responder as entrevistas. No decorrer dos texto serão expostas as respostas dadas pelo o grupo de professores e pela coordenadora pedagógica às perguntas feitas. Os sujeitos entrevistados são 3 (três) do sexo feminino e $\mathrm{I}(\mathrm{um}$ ) do sexo masculino, estende-se que o grupo de profissionais da escola é misto, sendo que a maioria é do sexo feminino, indo de encontro com a ideia de a educação é um setor com um numero expressivo de mulheres.

Durante a entrevista foram feitas cinco perguntas para os professores e cinco para a Coordenadora Pedagógica. A primeira pergunta feita para os professores indagava-os sobre como os mesmo viam a formação continuada para professores. E de acordo com as 
resposta obtidas à essa pergunta percebe-se que ambos dão grande importância para esse processo.

A formação Continuada é muito importante, indispensável e determinante no processo do ensino e aprendizagem que acontece na escola. Porém, essa formação não tem sido ofertada de maneira eficiente, tem oferecido muitas vezes programas e projetos distantes da realidade dos professores. $\left(\mathrm{P}_{2}\right)$

Vejo a Formação Continuada para professores como um meio essencial para que o profissional atuar na área mais seguro e situado no que lhe é proposto fazer. Quanto mais aperfeiçoamento profissional, maiores serão os frutos que colheremos através do trabalho docente. $\left(\mathrm{P}_{3}\right)$

Quando os professores relatam sobre a importância da formação, sente-se que eles almejam que esse processo seja levado mais à serio.

Já quando são perguntados sobre como essas formações tem ajudado a melhorar suas práticas pedagógicas, percebe-se que ah uma sintonia nas falas.

Essa formação é que irá determinar a melhoria de nossas práticas pedagógicas, afinal, a formação continuada tende a ser carregada de inovações para a aplicação do ensino. Sendo assim, quanto mais se forma no âmbito profissional, mais irá refletir nas práticas de ensino. $\left(\mathrm{P}_{3}\right)$.

A formação continuada vai influenciar diretamente na mudança e reforma na pratica pedagógica, afinal a formação continuada é maior carência para um professor recém-formado, que apesar das disciplinas de estagio, não tem a noção real das dificuldades encontradas no chão da escola. A melhoria das praticas pedagógicas depende de uma formação que ofereça possibilidades reais de aplicabilidade pratica no contexto escolar dos alunos atuais, [...] e não uma formação baseada em experiências das décadas passadas[...]. $\left(\mathrm{P}_{2}\right)$

O aprimoramento das praticas docente por meio da formação continuada do professor, é necessário para assegurar que o processo de ensino e aprendizagem seja realizado de forma positiva e que promova aprendizagem significativa. Acredito que o professor que tem um acompanhamento continuado é um pesquisador capaz de refletir, diagnosticar, planejar e intervir positivamente na realidade que atua. $\left(\mathrm{P}_{\mathrm{I}}\right)$.

Percebe-se que diante dos relatos dos professores sobre a importância da formação continuada para a melhoria das praticas pedagógicas, compreendeu -se que ambos acham importantíssimas, mas por outro lado, vê-se que consideram as formações ofertadas, ineficazes, carentes de praticas inovadoras. 
Durante a entrevista foi indagado aos professores de que formas essas formações lhes auxiliam no dia a dia da sala de aula. E analisando as respostas obtidas percebe-se que eles conseguem aproveitar ao Maximo o que adquirem nas formações.

\begin{abstract}
Como educadora percebo que a formação continuada me auxilia sim, na melhoria do processo de ensino e aprendizagem, uma vez que a complexidade da ação docente aumenta a cada dia. Seja por fatores intra e/ou extraescolares é perceptível os iço desafios encontrados na sala de aula são diversos e vão desde as mudanças imposta pela sociedade em relação à família, aos valores, as tecnologias até as dificuldades de aprendizagem que requer que o professor tenha habilidade de gerir tais situações satisfatoriamente. Para lidar com tudo isso, o acompanhamento pedagógico continuado é imprescindível, pois a formação continuada do professor oportuniza o estudo e a reflexão a cerca de tais questões e certamente, esse aprofundamento, seja ele por meio de literatura ou por meio da analise da realidade, ajuda a promover um ambiente de ensino e aprendizagem que atenda ou ao menos se aproxime das reais necessidades dos alunos favorecendo, assim, a construção de ação educativa integral,significativa e transformadora.(PI).
\end{abstract}

Dessa maneira presume-se que os professores entrevistados acreditam no poder das formações continuadas como formas de melhoramento de suas praticas pedagógicas e também como melhoramento profissional tornando-se mais atuante e eficaz no seu trabalho.

\begin{abstract}
A formação deve estimular uma perspectiva critico-reflexiva, que forneçam aos professores os meios de um pensamentos autônomo e que facilite as dinâmicas de autoformação participadas. Está em formação implica um investimento pessoal, um trabalho livre e criativo sobre os percursos e os projetos próprios com vista à construção de uma identidades, que é também uma identidade profissional. (NÓVOA,1997).
\end{abstract}

No decorrer da entrevista os professores participantes da pesquisa responderam sobre a importância do coordenador pedagógico no processo de formação continuada, veja a seguir os relatos:

É de importância imprescindível. A coordenação pedagógica é a base para qualquer trabalho no meio educacional e não se faz diferente na formação continuada. Uma coordenação eficaz torna todo coro docente inspirado a trabalhar com amor e dedicação. $\left(\mathrm{P}_{3}\right)$

O coordenador é peça fundamental na formação continuada, porem essa nação de coordenador formador ainda esbarra no cotidiano da escola. O próprio coordenador não se assume como formador ou então quando assume essa função é barrado pelas outras tantas funções que lhes são atribuídas. $\left(\mathrm{P}_{2}\right)$. 
O coordenador pedagógico é um agente fundamental para a efetivação da proposta pedagógica da escola, uma vez que é ele que articula e facilita as ações a serem desenvolvidas. Considero o coordenador pedagógico como um mediador, um facilitador no processo de formação continuada para professores. (PI).

Ao final da entrevista o grupo respondeu como vem endo conduzido o processo de formação continuada pela coordenadora pedagógica da escola em o grupo atua. Analisaremos agora as respostas ofertadas pelo grupo.

\begin{abstract}
$\mathrm{Na}$ minha escola, assim como nas outras da esfera municipal, não é atribuído ao coordenador pedagógico essa função formadora, e sim a função fiscalizadora da escola, da dinâmica do trabalho do professor e do processo de ensino e aprendizagem. Portanto, a formação dentro da escola não chega a ser concretizada. $\left(\mathrm{P}_{2}\right)$.
\end{abstract}

Penso que no ambiente escolar ainda existe uma falta de clareza em relação as reais atribuições do coordenador pedagógico, que na maioria das vezes concentrase mais em questões administrativas e burocráticas do que realmente naquilo que considero sua função principal, que é acompanhar e dar suporte ao trabalho pedagógico e aprendizagem dos alunos. $\mathrm{N}$ a escola sinto falta dessa formação continuada, do acompanhamento nos planejamento, na proposição e construção de intervenções para a melhoria do processo de ensino e aprendizagem. De fato, a formação continuada de professores se dá apenas em encontros oferecidos pela secretaria de educação, onde são propostos ações e projetos que muitas vezes não se adéquam a realidade das escolas.(PI).

De acordo com o que se ver nos depoimentos dos professores em relação a formação que deve acontecer dentro da escola, percebe-se que de fato isso não vem ocorrendo, e vários são os fatores que contribuem para isso, como a falta de definição das funções do coordenador pedagógico e até mesmo a forma como é conduzido esse processo pela secretaria de educação do município. Durante a pesquisa bibliográfica ficou bem claro que não é raro as distorções do papel do coordenador pedagógico.

Em função das múltiplas demandas, o coordenador pedagógico é solicitado a realizar variadas tarefas que não são de sua responsabilidade. São demandas que, apesar de fazerem parte da escola, não podem ser consideradas intrínsecas as suas atribuições. (COLARES e ROCHA,2016 p.83).

Assim percebe-se claramente que o coordenador pedagógico é sobrecarregado de funções que muitas vezes lhes são atribuídas equivocadamente, tirando-o do seu principal objetivo formar seus professores e com eles melhorar o processo de ensino e aprendizagem dos alunos. 
Após encerramos as entrevistas co os professores, foi a vez de conversarmos com a coordenadora pedagógica da escola, que foi bastante atencioso par doto esse momento e se disponibilizou a responder todas as perguntas.

De inicio ela nos falou um pouco da realidade da escola, relatou que a escola tem um publico grande, que nesse ano de 2018(dois mil e dezoito) a escola conta com um numero de 668(seiscentos e sessenta e oito) alunos e que dispõem das três níveis de ensino: Educação Infantil; Fundamental I e Fundamental II, e ela afirma que devido essa variedade o trabalho dela se torna as vezes ineficaz, uma vez que só existe ela como coordenadora pedagógica na escola para atender toda essa demanda de aluno e professores.

Durante a entrevista foi respondendo os questionamentos e quando foi questionada sobre as funções do coordenador pedagógico e principalmente a de formador e qual a importância dessa função para a escola respondeu o seguinte:

Para uma mudança educativa é essencial perceber as possibilidades e necessidades didáticas pedagógicas de cada nível educativo, e é de suma importância que o coordenador pedagógico diante das inúmeras funções que lhes são atribuídas, ser capaz não só de perceber,as necessidades de cada nível, mas também explicitar problemas e desafios, promovendo o compartilhamento de práticas e resolução de problemas. Todos somos sabedores do acumulo de funções que carrega o coordenador pedagógico em seu dia a dia, e dentro desse contexto, a função de formador requer tempo não só para estudo, mas para analise de situações problemas que surgem no cotidiano escolar. Então a função de formador um pouco em desuso por falta da disponibilidade de tempo e por termos uma realidade de três níveis de ensino em uma mesma escola, e assim sendo, a sobrecarga do coordenador o impede com melhor atuação e melhor resultados a função tão indispensável para que melhoremos não só os índices de leitura, de escrita mas também as práticas pedagógicas de nossos professores.(CP)

Dessa maneira ficou bem explicito que a formação continuada na escola envolvida na pesquisa na é de fato concretizada ou não se faz da forma que deveria ser, e dos principais motivo de isso não ocorrer como alguns professores já haviam mencionado e agora a coordenadora também destaca é o acumulo de funções do coordenador pedagógico que muitas vezes fica fazendo o que não é da sua alçada.

Várias demandas vão parar nas mãos do coordenador pedagógico. Com tantas atribuições cotidianas, seu trabalho muito das vezes torna-se inócuo, e muitos acabam não conseguindo desenvolver uma importante função dentro da escola: 
ajudar na formação continuada dos professores. Portanto, fica evidenciado que a prática usada por gestores educacionais em fazer do coordenador uma espécie de "faz tudo" nas instituições educacionais, gera uma série de conflitos educacionais. Se por um lado o desenvolvimento das atividades cotidianas da escola é conduzido normalmente,[...] Por outro lado, a real função de cuidar integralmente do processo pedagógico e na formação continuada dos professores, fica relegada às apenas pequenas intervenções que pouco acrescenta nas práticas educacionais empregadas cotidianamente pelos professores.(SILVA,2013, p.22 e 23.).

Durante todo o período observação da escola pode-se perceber claramente esse desvio de função por parte do coordenador pedagógico que quase que todo o tempo em que fica no colégio, se detém muito nos fazeres burocráticos da escola e dessa maneira fica impossível realizar a função formadora.

No decorrer da entrevista a coordenadora foi indagada sobre como ela ver a aceitação dos professores em relação a formação continuada, partindo do pressuposto de que funcionaria como um aprimoramento profissional.

Temos em nosso pais um cenário triste de desvalorização do profissional da educação, e assim sendo, é gerado nesses profissionais um quadro de desestímulo alarmante e muito preocupante, pois estamos indo em diferentes direções, onde os governantes cobram uma educação de qualidade sem dar condições necessárias para isso. Diante dessa problemática de desvalorização e desrespeito ao profissional é visível que mesmo tendo consciência da importância da formação da melhoria de suas pratica pedagógicas, os professores se sentem desmotivados e nem sempre dão o devido valor a esses momentos.(CP).

Ao observar a fala da coordenadora em relação a importância dada pelos professores aos momentos destinados a formação continuada, encontra-se um desencontro em relação a fala dos professores da coordenadora, pois quando os professores foram indagados sobre isso, ambos responderam que acham muito importante, porem pouco ou nunca ocorrem e quando ocorrem é algo que não vai muito de encontro com a realidade da escola. E já coordenadora entende que os professores não valorizam os momentos por serem desvalorizados pelos governantes.

Continuando com a entrevista, foi questionada com a coordenadora sobre como ela realiza essas formações com os seus professores. 
Em vários momentos de estudos sempre ouço o termo gestão democrática, porem em situação do dia a dia constato que gestão democrática não se faz com palavras, mas com ações concretas. Sabe-se que professores querem ter "vez e voz", então procuro sempre em nossos momentos coletivos, trabalhar o que mais aflige os professores, e assim dar a eles a oportunidade de não só explicitar problemas, mas também apontar soluções. A formação continuada permite que agregue conhecimentos e seja capaz de transformar o contexto profissional e escolar.(CP).

Analisando a resposta da coordenadora percebe-se rodeios ao responder a pergunta e o que se constata é que a formação continuada ofertada na escola se resume a reuniões e não a momentos de estudos.

Em sua ação formadora docente, demonstra a sua personalidade, expõe suas ideias, saberes ,leituras e conhecimentos no decorrer das atividades desenvolvidas nos encontros de horário complementar. O coordenador pedagógico é um "artesão" construindo permanentemente seus saberes, nas relações travadas entre os demais membro da comunidade escolar(CHARLOT,2005,P.22)

Depois a coordenadora pedagógica respondeu sobre se depois desses momentos reflexivos havia alguma melhora no processo de ensino e aprendizagem dos alunos.

A reflexão e a avaliação é importante em qualquer área profissional, porem na área educacional ambas são imprescindíveis, e os alunos são o reflexo do que recebem dos seus professores no cotidiano de sua vida escolar, dessa maneira se tivermos professores preparados e motivados teremos alunos com essas mesmas características. Dentro da minha realidade escolar tenho excelentes profissionais, que embora não tendo as melhores condições de trabalho, realizam brilhantemente sua função. Com certeza percebo a empolgação dos alunos a cada metodologia diferente, a cada palavra de incentivo e cada exemplo vivenciado a partir de nossos professores. (CP).

Em consonância com o supracitado, é visível que a escola caminha com grandes dificuldades físico-estruturais, mas que apesar de tudo, possui um recurso humano eficiente. Assim no final da entrevista a pergunta para a coordenadora foi quais os maiores desafios enfrentados por ela para realizar essas formações.

Como já foi um pouco explicado temos em nossa escola um quantitativo de alunos muito elevado, temos os três níveis de ensino, assim sendo, cada nível com suas dificuldades e peculiaridades, e devido as múltiplas funções do coordenador pedagógico, o maior desafio é ter tempo disponível para estudos e preparação de formações que sejam adequadas a cada nível dentro das dificuldades que cada um apresenta. Alem de termos uma estrutura física precária que nos impossibilita planejar ações que estejam voltada para cada nível de ensino.(CP). 
Percebe-se que a coordenadora se sente muito atarefada e não consegue desenvolver suas reais atribuições devida a grande demanda atividades atribuídas a ela.

Parece já histórico ver em nossas escolas, principalmente na rede pública, o coordenador pedagógico tornar-se um profissional que faz tudo o que lhe é pedido.[...] o cotidiano do coordenador pedagógico é bastante diversificado $e$ muito das vezes fica muito aquém do que é necessário em relação às práticas pedagógicas ideais.(SILVA, 2013, p.22)

Após analisarmos a escola escolhida para a pesquisa os depoimentos dos professores e a coordenadora envolvidos na pesquisa percebe-se que a formação continuada considerada pela rede municipal são aquelas formações ofertadas pela secretaria de educação do município que ocorrem mensal, bimestral e/ou trimestral, com os técnicos da secretaria responsáveis por cada área, pois vê-se claramente que a ideia de formação continuada feita através do coordenador pedagógico não realizadas, a função formadora dos coordenadores municipais fica em desuso. Algo também muito claro é que, o coordenador escolar municipal não conhece de fato suas atribuições dentro da escola e, acaba por fazer tudo e não fazer nada. Pois é bem claro que qualquer instituição onde as pessoas inseridas sabem e fazem a sua função são as melhores, e na escola não pode ser diferente, talvez esse seja o maior desafio das escolas (principalmente as municipais) deixar bem claro qual a função de cada agente para que realmente a coisa aconteça de forma satisfatória.

\section{CONSIDERAÇÕES FINAIS}

Diante do que foi pesquisado analisado e escrito, ficou evidente a necessidade de uma clareza maior sobre as atribuições do cargo de um coordenador pedagógico. Precisa-se compreender que o mesmo não é uma espécie de faz tudo. O que acontece na prática é que o coordenador se sobrecarrega de outras funções, deixando de lado a rotina de formador, a qual se deve dar prioridade, conhecendo assim essa função em sua essência. Quando o coordenador assume outros papeis na escola, ele é desviado de sua função essencial: formar professores. Organizar os horários de uso da biblioteca, dar uma força aos funcionários na época de matrícula e conversar com as famílias, demanda tempo demais, desviando a atenção do coordenador para outras funções que não são de sua competência. Esses 
entraves dificultam a atenção e excelência do papel do coordenador pedagógico, o qual devia concentrar-se na formação em serviço dos professores, que é a sua função prioritária. Os próprios coordenadores não conhecem as fronteiras do seu papel e, por isso, aceitam todas as demandas que lhe são compelidas, fazendo coisas demais por não terem o entendimento de que são verdadeiros formadores.

Da mesma forma que o professor planeja boas atividades para seus alunos, o coordenador necessita planejar com antecedência a discursão e o exercício dos docentes. Um contexto bem planejado dá ao coordenador pedagógico respaldo sobre seus objetivos para cada encontro e estratégia formativa selecionada. Revelando o cuidado e a atenção de formador com o seu grupo de professor. Com essa reflexão espera-se ampliar a compreensão do papel do coordenador pedagógico na escola contemporânea.

Observa-se que o processo de ensino-aprendizagem depende da organização institucional, da capacitação de seus formadores, do exercício de reflexão-ação, para problematizar a formação continuada, entre o formando (docente) e o incentivador (coordenador pedagógico). Nesse espaço se expõe a função do coordenador, que traz entre suas ações, a integração e articulação dos membros da comunidade escolar. Pesquisas como estas tem mostrado que o caminho para a transformação passa pela coordenação pedagógica, que trabalha em prol do avanço no processo ensino e aprendizagem.

\section{REFERENCIAIS BIBLIOGRÁFICOS}

ASSUNÇÃO, Ozélia Horácio Gonçalves e FALCÃO, Rafaela de Oliveira: O coordenador pedagógico e a formação continuada de professores: uma pesquisa-ação no município de fortaleza. Fortaleza, 2015.

BOCCATO, V. R. C. Metodologia da pesquisa bibliográfica na área odontológica e o artigo científico como forma de comunicação. Rev. Odontol. Univ. Cidade São Paulo, São Paulo, v. I8, n. 3, p. 265-274, 2006

BOCCATO, V. R. C. Metodologia da pesquisa bibliográfica na área odontológica e o artigo científico como forma de comunicação. Rev. Odontol. Univ. Cidade São Paulo, São Paulo, v. I8, n. 3, p. 265-274, 2006

BRASIL, Lei de Diretrizes e Bases da Educação Nacional. Lei no 4.024 de 20 de Dezembro de i96r. 
BRASIL, Lei de Diretrizes e Bases da Educação Nacional. Lei no 9.394, de 20 de dezembro de 1996.

CANDAU, V.M.F. Universidade e formação de professores: que rumos tomar? In. . (Org.). Magistério, construção cotidiana. 5 ed. Petrópolis, Vozes, 2003.

CAPELINI, Helena de Andrade A (re) significação do Trabalho Docente no espaço escolar: currículo e formação (Universidade de Ribeirão Preto -

CARVALHO, Laerte Ramos de. Introdução ao estudo da História da Educação Brasileira: o desenvolvimento histórico da educação brasileira e a sua periodização. São Paulo, 1972.

CHARLOT, B. Relação com o saber, formação de professores e globalização: questões para a educação hoje. Porto Alegre: Artes Médicas, 2005.

COLARES, Maria Lílian Imbiriba Sousa e ROCHA, Solange Helena Ximenes: O Coordenador pedagógico no cotidiano escolar. Editora CRV, Curitiba. 2016 contribuições para o desenvolvimento profissional dos professores. Rev. Diálogo Educ., Curitiba, v. Io, n. 30, p. 285-300, 2010.

CUNHA, M. I. O bom professor e sua prática. Campinas: Papirus, I8 ed, 2006.

FERREIRA, Naura Silva C. (Coord.). Supervisão educacional para uma escola de qualidade: da formação à ação. 4 ed. São Paulo: Cortez, 2003.

FLICH, Uwe: Método de pesquisa- Introdução à pesquisa qualitativa. Tradução Joice Elias Costa $3^{\circ}$ Edição, Artmedid Editora S.A. São Paulo. 2009.

GONÇALVES, Elisa Pereira. Iniciação à pesquisa científica. Campinas, SP: Editora Alínea, 200r.

GONÇALVES, Elisa Pereira. Iniciação à pesquisa científica. Campinas, SP: Editora Alínea, 200I.

LIBÂNEO, José Carlos. Democratização da sua escola pública: a pedagogia crítico-social dos conteúdos. I8 ed. Loyola: São Paulo. 2002.

LIBÂNEO, José Carlos. Organização e gestão da escola: teoria e prática. 5 ed. Goiânia, Alternativa, 2004.

LIMA, Paulo Gomes; SANTOS, Sandra Mendes dos. O coordenador pedagógico na educação básica: desafios e perspectivas. Educere et educare: Revista de Educação, v. 2, n. 4, p. 77-9o, Disponível em: $<$ http://www.ufgd.edu.br/faed/nefope/publicacoes/ocoordenadorpedagogico na-educacao-basica-desafios-e-perspectivas $>$. Acesso em: io jul. 2018.

LÜCK, Heloísa. Ação integrada: administração, supervisão e orientação educacional. 28 ed. Petrópolis, Rio de Janeiro: Vozes, 20II. 
MIRANDA, Rosane Gonçalves de Oliveira: A Atuação do Supervisor Educacional no Âmbito Escolar, Rio de Janeiro. 2012.

NISKIER, Arnaldo. Educação Brasileira: 500 anos de História. Rio de Janeiro: FUNARTE, 200I.

NÓVOA, A. Formação de professores e profissão docente. In: NÓVOA, A. (Coord.) Os professores e a sua formação. 3. ed. Porto: Publicações Dom Quixote, 1997.

NÓVOA, Antônio. Formação de professores e formação docente. In: Nóvoa, Antônio. (Org.) Os professores e sua formação. Lisboa: Dom Quixote, 1992.

PIRES, Ennia Débora Passos Braga. A prática do coordenador pedagógico - limites e perspectivas. Dissertação, (Mestrado em Educação) - Faculdade de Educação, Universidade Estadual de Campinas, 2004.

RIVAS, Noeli Prestes Padilha; PEDROSO, Cristina Cinto Araujo .; LEAL, Maria

ROMANOWISK, Joana Paulin e MATINS, Pura Lucia Oliver: Formação continuada:

SAVIANI, D. A Supervisão Educacional em perspectiva histórica: da função à profissão pela mediação da ideia. In Carapetto, N. S. (org.) Supervisão educacional para uma escola de qualidade. São Paulo: Ed. Cortez, 2002.

SILVA, Ana Paula dos Santos: A Coordenação Pedagógica no Contexto da Realidade Escolar Brasileira, Brasília, 2013.

SOUZA, A. A.; RAMOS, P. Relacionamento interpessoal nas organizações. Instituto Catarinense de Pós-Graduação. 2004. I2p. Disponível em: 〈http://www.icpg.com.br〉 Acesso em: ro jul. 2018.

SOUZA, A.R. Perfil da gestão escolar no Brasil. Tese de doutorado. São Paulo, Pontifícia Universidade Católica de São Paulo, 2006.

SPÒSITO, Marília P. Educação, gestão democrática e participação popular. In: BASTOS, J.B (org.) Gestão democrática. Rio de Janeiro: DPA. 2005.

TARDIF, M. Saberes docentes e formação profissional. 7 ed. Petrópolis: Vozes, 2004. UNAERP e Faculdade de Filosofia Ciências e Letras - USP - RP) -2005

VEIGA, Ilma P.A. Repensando a didática. 2I ed., Campinas, SP: Papirus, 2004, Cap.I 